\title{
TRIAL WITH RED FILTER IN THE TREATMENT OF ECCENTRIC FIXATION*
}

\author{
BY \\ J. B. COWLE \\ Department of Ophthalmology and Eye Health, University of Sydney \\ AND \\ J. H. KUNST AND A. M. PHILPOTTS (ORTHOPTISTS) \\ Medical Eye Service of New South Wales
}

FoLLOwING the preliminary reports of Brinker and Katz (1963) and Binder, Engel, Ede, and Loon (1963) on the possible use of a red filter in the management of eccentric fixation, we tried this method of treatment in a series of eighteen cases, ten of which completed the investigation. Six of these were cases of eccentric fixation of the paramacular type, two of the parafoveal type, and two were cases of fixation loss. Our results are compared with those of the authors named above and with the results of a recent survey on pleoptic treatment. No attempt was made to differentiate between eccentric fixation and eccentric viewing in any of these investigations or in our own work.

\section{Method}

The red filter used in this study was a Kodak Wratten gelatin filter No. 25 which transmits visible light in the region of 580-700 millimicrons and has a luminous transmittance of 22.5 per cent. This filter, allowing very little stimulation of rods but permitting stimulation of cones, when placed in front of an eye with eccentric fixation will encourage use of the fovea in preference to the eccentric fixation point.

We use the filter mounted between glass in a clip-on device which can be worn over spectacles with the unaffected eye occluded. It is worn for periods of 4 to 6 hours a day in front of the eccentrically fixing eye and at all other times this eye is occluded. In the course of this investigation the filter treatment was carried on for an average period of about 7 months, at the end of which, fixation became central in those cases which responded to treatment. In order to be certain of maintaining central fixation, the filter was continued for short periods each day after occlusion had been changed to the normal eye. Occlusion of the normal eye was then continued for approximately 5 months in most instances.

\section{Results}

The data concerning the ten patients are given in the Table, overleaf. Six patients did not complete the investigation and one had a congenital abnormality of the optic disc. These seven patients have been excluded from the analysis together with one

* Received for publication November 8, 1965.

+ Address for reprints: Department of Ophthalmology and Eye Health, University of Sydney, N.S.W., Australia. 
Clinical Datâ?

\begin{tabular}{|c|c|c|c|c|c|c|c|c|}
\hline \multirow{3}{*}{$\begin{array}{l}\text { Case } \\
\text { No. }\end{array}$} & \multirow{3}{*}{$\begin{array}{c}\text { Age } \\
\text { (yrs) }\end{array}$} & \multirow{3}{*}{ Sex } & \multirow{2}{*}{\multicolumn{2}{|c|}{ Refractive Error }} & \multicolumn{4}{|c|}{ Visual Acuity } \\
\hline & & & & & \multicolumn{2}{|c|}{ Before Treatment } & \multicolumn{2}{|c|}{ After Treatment } \\
\hline & & & Right & Left & Right & Left & Right & Left \\
\hline 1 & 4 & $\mathbf{M}$ & $+1 \cdot 25 \mathrm{D} \mathrm{sph}$ & $+0.75 \mathrm{D}$ sph. & $\frac{6}{18-12}$ & $\frac{3}{60}$ & $\frac{6}{12}$ & $\frac{6}{12}$ \\
\hline 2 & 9 & $\mathbf{M}$ & Nil & Nil & $\frac{6}{36}$ & $\frac{6}{6}$ & $\frac{6}{12}$ & $\frac{6}{6}$ \\
\hline 3 & 10 & $\mathbf{M}$ & Nil & Nil & $\frac{6}{36}$ & $\frac{6}{6}$ & \multicolumn{2}{|c|}{ No Improvement } \\
\hline 4 & 9 & $\mathbf{M}$ & $-0.5 \quad \mathrm{D}$ sph. & $-0.25 \mathrm{D}$ sph. & $\frac{6}{18}$ & $\frac{6}{6}$ & $\frac{6}{9}$ & $\frac{6}{6}$ \\
\hline 5 & 4 & $\mathbf{M}$ & $\frac{+1.75 \mathrm{D} \text { sph. }}{+1.5 \text { D cyl. }}$ & $\frac{+2.25 \mathrm{D} \mathrm{sph}}{+1 \cdot 5 \text { D cyl. }}$ & $\frac{6}{9}$ & $\frac{6}{36}$ & $\frac{6}{9}$ & $\frac{6}{12}$ \\
\hline 6 & 4 & $\mathbf{M}$ & $+3 \cdot 5$ D sph. & $+4 \cdot 25 \mathrm{D} \mathrm{sph}$ & $\frac{6}{6}$ & $\frac{1}{60}$ & $\frac{6}{6}$ & $\frac{6}{6}$ \\
\hline 7 & 9 & $\mathbf{M}$ & $\begin{array}{ll}+3.5 & \text { D sph. } \\
+1.5 & \text { D cyl. }\end{array}$ & $\begin{aligned} &+2 \cdot 5 \text { D sph. } \\
&+2 \cdot 0 \text { D cyl. }\end{aligned}$ & $\frac{6}{6}$ & $\frac{6}{24}$ & $\frac{6}{6}$ & $\frac{6}{18}$ \\
\hline 8 & 4 & $\mathbf{F}$ & $\begin{array}{ll}+4.0 & \text { D sph. } \\
+0.5 & \text { D cyl. }\end{array}$ & $\begin{aligned}+0.5 & \text { D sph. } \\
+0.5 & \text { D cyl. }\end{aligned}$ & $\frac{6}{60}$ & $\frac{6}{12}$ & $\frac{6}{18}$ & $\frac{6}{9}$ \\
\hline 9 & 6 & F & $\frac{+1.25 \mathrm{D} \mathrm{sph} .}{+0.25 \mathrm{D} \mathrm{cyl} .}$ & $\frac{+1.0 \text { D sph. }}{+0.25 \mathrm{D} \mathrm{cyl} .}$ & $\frac{6}{18}$ & $\frac{6}{6}$ & $\frac{6}{12}$ & $\frac{6}{6}$ \\
\hline 10 & 6 & $\mathbf{F}$ & $+1.75 \mathrm{D}$ sph. & $\frac{+1.0 \text { D sph. }}{+0.75 \text { D cyl. }}$ & $\frac{6}{6}$ & $\frac{6}{24}$ & $\frac{6}{6}$ & $\frac{6}{6}$ \\
\hline
\end{tabular}

other who probably had central fixation. In all but one of the six cases of eccentric fixation of the paramacular type in this series, central fixation was restored. Two cases of parafoveal fixation remained unaltered. In the two cases of fixation loss central fixation was restored. Of the eight cases of eccentric fixation, five responded with a visual acuity of $6 / 12$ or better and two with a visual acuity of $6 / 18$; in one vision did not improve and there was no alteration in fixation. Two of the patients are still under treatment. In the two cases of fixation loss full vision was obtained.

\section{Discussion}

These results indicate that eccentric fixation can be restored to normal in most instances, but that maximum visual acuity is not usually obtained, though an improvement to $6 / 12$ can be expected. Although it is not possible to draw definite conclusions from the two cases of fixation loss, it is likely that normal fixation and normal vision may be achieved eventually. In the series reported by Binder and others (1963), in all but one of eight cases of eccentric fixation of the paramacular type, central fixation was restored and a general improvement of visual acuity to 6/12 was obtained. However, in order to achieve our results, we found it necessary to use the filter for a 
for Ten Patients

\begin{tabular}{c|c|c|c}
\hline \multicolumn{2}{c|}{ Fixation Point } & $\begin{array}{c}\text { Time with } \\
\text { Filter } \\
\text { (mths) }\end{array}$ & Comments \\
\hline Initial & Feripheral & 3 & \\
\hline Para-macular & Central Unsteady & 4 & \\
\hline Para-macular & Unaltered & 10 & \\
\hline Para-foveal & Unaltered & 10 & \\
\hline Para-macular & Central Unsteady & 9 & Still on treatment with occlusion \\
\hline Peripheral & Central & 6 & Originally left now right convergent strabismus \\
\hline Para-macular & Central Unsteady & 2 & \\
\hline Para-macular & Central Unsteady & 9 & Still on treatment \\
\hline Para-foveal & Unaltered & 6 & \\
\hline Para-macular & Central Unsteady & 10 & Originally left now right convergent strabismus \\
\hline
\end{tabular}

period of 7 months compared to the average period of $2 \frac{1}{2}$ months reported by Binder and his colleagues. The one case of fixation loss in their series also recovered central fixation and normal vision. It appears to us that in the series of Brinker and Katz (1963), six of the eight cases were probably suffering from fixation loss rather than eccentric fixation. These were all restored to central fixation, but with an average visual acuity of less than $6 / 12$. Of the two definite cases of eccentric fixation in this group, one achieved 6/18 vision with restored fixation. It should also be noted that most cases in this series had had previous treatment by occlusion, and that the filter treatment was used only for approximately 6 weeks; it is thus possible that with longer use further improvement could have been obtained. It is of interest to compare the results of the two groups of patients with adequate red filter treatment to the results of a recent survey by Gillies and Syme (1965) of a series which had pleoptic treatment. For purposes of comparison only those of their patients who had not had previous occlusion are considered. Of 28 patients, only eight obtained a visual acuity of $6 / 18$ or better, whereas of the nineteen cases in the combined series of Binder and others (1963) and ourselves, without previous treatment by occlusion and having a specified type of abnormal fixation, only one failed to achieve this improvement. 


\section{Conclusions}

The red filter may have a useful role as a selective occluder in cases of fixation loss as well as in cases of eccentric fixation. However, in both conditions, to achieve good results, it must be used for more than 7 months followed by 5 months occlusion of the normal eye, a total treatment time of 12 months. The use of a red filter in the visuscope was considered by previous authors to be of prognostic value when fixation switched from eccentric to central during examination. This was not found by us to be satisfactory, as we were unable to define the macula clearly on observation through the filter. It will be necessary to compare further results of red filter treatment with those of conventional occlusion and of pleoptic methods, to confirm that the improvement results from filter treatment.

We are grateful to Ass. Prof. W. Burke for his helpful criticism in the preparation of this paper.

\section{REFERENCES}

Binder, H. F., ENGEL, D., EDE, M. L., and LoON, L. (1963). Amer. orthopt. J., 13, 64. BRINKER, W. R., and KATZ, S. L. (1963). Amer. J. Ophthal., 55, 1033.

Gillies, W. E., and Syme, A. (1965). Med. J. Aust., 1, 390. 